\title{
A Novel Compact Ultra-wideband Printed Dipole Antenna with Tapered Slot Feed
}

Tyzh-Ghuang Ma* and Shyh-Kang Jeng Graduate Institute of Communication Engineering, Rm. 545 National Taiwan University, Taipei, Taiwan 10617, R.O.C Email: skjeng(a)ew.ee.ntu.edu.tw

\begin{abstract}
Ultra wide band (UWB) techniques draw more and more attention in recent years. Nevertheless, it is not easy to find a proper antenna for such systems. In this paper, we propose a novel compact antenna suitable for ultra-wideband applications. This new antenna is characterized by its ultra-wideband quasi-omnidirectional patterns in the $H$-plane. Measurement results demonstrate a $4: 1$ bandwidth for both input return loss as well as $H$-plane patterns.
\end{abstract}

\section{Introduction}

Ultra wide band (UWB) techniques have received more and more attention nowadays in the wireless world owing to its high transmission rate, extremely low power consumption and simple hardware configuration over conventional wireless communication systems. It can coexist with other radio systems without causing harmful interference and gives the possibility to ease the crowded frequency spectrum in modern days. However, it is not easy to design a proper ultra-wideband antenna to accomplish the critical requirements of such a system, including ultra-wide bandwidth, omnidirectional pattern, compact size and low cost. Most antennas reported for ultra-wideband applications are three-dimensional structures and hence cannot satisfy the requirements of compact size and easy fabrication [1][2]. Tapered slot antenna and its variations have inherently wideband characteristics with endfire patterns [3][4], while printed dipole antennas are with moderate bandwidth and have almost omnidirectional patterns in the $H$-plane [5]. In this paper, we combine the features of these two planar antennas and achieve a novel design that fits all the requirements for the antenna used in an ultra-wideband system, i.e., compact size, low cost, easy to fabricate, satisfactory bandwidth and quasi-omnidirectional pattern. This antenna will also be suitable to other wideband or multiband applications.

\section{UI. Antenna Design}

Tapered slot antenna exhibits wideband characteristic that is attractive to many applications. Dual exponentially tapered slot antenna improves the beamwidth performance as well as the directivity while roughly maintains other properties of the original tapered slot antenna [4]. To obtain a quasi-omnidirectional pattern, it is desired to deliver energy to the reverse side of the antenna aperture. To this end, we reverse the direction of the outer half of the dual exponentially tapered strips and modify the tapered profiles with two elliptical shapes to smooth the transition near the aperture. This new antenna, which behaves like the conventional printed dipole antenna but possesses ultra-wideband characteristics, is in essence a printed dipole antenna with a 
novel tapered slot feed. In addition, more compact antenna size is achieved with curved strips. To further broaden the antenna bandwidth without scaling, an additional strip is added in front of the aperture to introduce an extra resonance in the low frequency range [6]. This strip also acts as a reflector and spreads energy more evenly around. Thus it is called a "reflector" in the rest of this paper. Note that both ends of the reflector are bended intentionally to facilitate the coupling from the aperture to the reflector. The final antenna geometry together with a microstrip line to slotline transition is shown in Fig. 1. The designed parameters are (unit: millimeter): $W_{s}=0.3$ $\mathrm{W}_{\mathrm{m}}=3, \mathrm{~W}_{\mathrm{l}}=\mathrm{W}_{2}=\mathrm{W}_{3}=7, \mathrm{~W}_{\mathrm{r}}=4, \mathrm{R}_{\mathrm{a}}=40.5, \mathrm{R}_{\mathrm{b}}=8.5, \mathrm{R}_{\mathrm{s}}=4.5, \mathrm{R}_{\mathrm{m}}=9, \mathrm{R}_{\mathrm{r}}=15.5$, $\theta_{\mathrm{m}}=90^{\circ}, \theta_{\mathrm{r}}=38^{\circ}, \mathrm{L}_{\mathrm{r}}=\mathrm{L}_{\mathrm{f}}=24.3, \mathrm{D}_{\mathrm{r}}=15, \mathrm{D}_{\mathrm{t}}=10$, and $\mathrm{D}_{\mathrm{f}}=20$. Note that this antenna is about one third in size of a tapered slot antenna with comparable return loss bandwidth.

\section{Measurement Results}

The antenna is fabricated on a low cost 1.6-mm-thick FR4 substrate. Although this substrate suffers from high dielectric loss for frequency higher than $6 \mathrm{GHz}$, it is valuable for a first-try design. Measured input return loss of the antennas with and without the reflector is shown in Fig. 2 and a bandwidth more than $4: 1$ is obtained. It also demonstrates that the reflector extends the lower edge of the available frequency band downward from 3.2 to $1.7 \mathrm{GHz}$. Nevertheless, it deteriorates the in-band performance to some extent, especially around $4 \mathrm{GHz}$. Careful adjustments of the length and the location of the reflector can produce acceptable performance throughout the band. The radiation patterns were measured in an anechoic chamber and the antenna gain was calibrated with a standard horn antenna. Figures 3 to 6 show the $H$-plane patterns measured from 1.8 to $6.8 \mathrm{GHz}$ with a $0.5 \mathrm{GHz}$ step. These figures indicate that ultra-wideband quasi-omnidirectional patterns are achieved in the $H$-plane and almost all the fluctuations are smaller than $10 \mathrm{~dB}$. A printed dipole antenna with small ground plane in its back side reveals quasi-omnidirectional $H$-plane patterns inherently, however, it is the novel tapered slot feed contributes to its ultra-wideband characteristics. Figures 7 and 8 show the $E$-plane patterns from 1.8 to $6.8 \mathrm{GHz}$ with a $1 \mathrm{GHz}$ step as well. These figures also exhibit acceptable performance although the patterns are more directive. The measured antenna gain is around $2-4 \mathrm{dBi}$ over the whole band except the upper end of the available frequency band. This is because the behavior of this antenna is more similar to that of the conventional tapered slot antenna providing the frequency is high. Figure 8 illustrates the variations of the antenna gain versus frequencies. The measured crosspolarization level in both planes is less than -10 $\mathrm{dB}$ and a typical result in the $H$-plane at $6.3 \mathrm{GHz}$ is shown in Fig.6.

\section{Conclusions}

A novel compact printed dipole antenna with tapered slot feed is proposed and proved to be eligible for ultra-wideband applications. Designs and parameter study will be explored further over low loss substrates.

\section{References}

[1] T.Taniguchi and T.Kobayashi, "An omnidirectional and low-VSWR antenna for ultra-wideband wireless systems", in Proc. IEEE RAWCON'02, pp. 145-148.

[2] W.F.McNaul, J.Glabe and B.Welge, "A low profile antenna for ultra-wide band 
applications," in IEEE Int. Symp. Antennas Propagat. Dig., San Antonio, TX, June 2002, pp.476-479

[3] J.Shin and D.H.Schaubert, "A parameter study of stripline-fed Vivaldi notch-antenna arrays," IEEE Trans. Antennas Progatat., vol. 47, No.5, pp. 879-886, May 1999.

[4] M.C.Greenberg and K.L.Virga, "Characterization and design methodology for dual exponentially tapered slot antenna," in IEEE Int. Symp. Antennas Propagat. Dig., Orlando, FL, July 1999, pp.88-91.

[5] C.Delaveaud and C.Brocheton, "Dual-band behavior of printed dipole," Electron. Lett., vol. 36 , No.14, pp. 1175-1177, July 2000.

[6] W.R.Deal, N.Kaneda, J.Sor, Y.Qian and T. Itoh, "A new quasi-Yagi antenna for planar active antenna arrays," IEEE Trans. Microwave Theory Tech., vol.48, No.6, pp.910-918, June 2000.

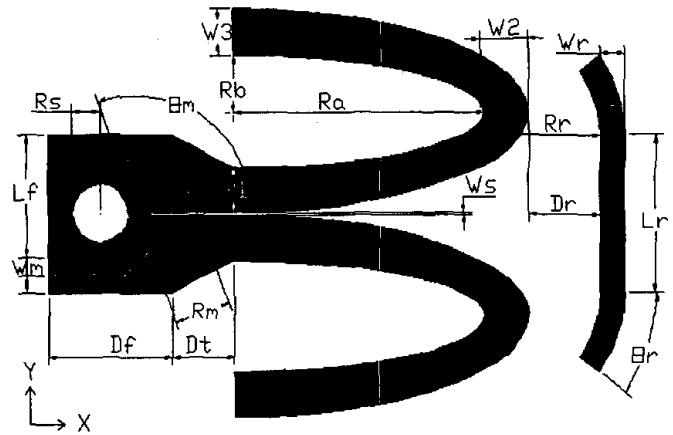

Fig.1. Antenna Geometry

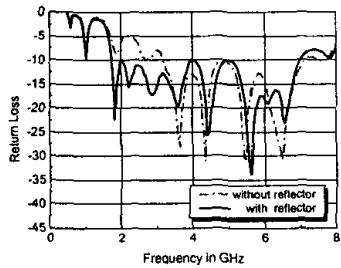

Fig.2. Return Loss of the antennas with and without the reflector

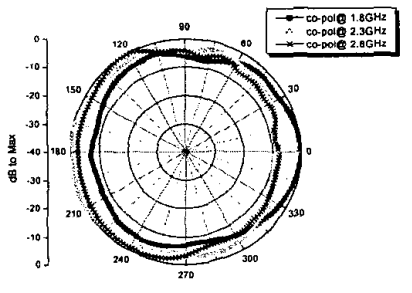

Fig.3. $H$-plane ( $x z$ plane) patterns at $1.8,2.3$ and $2.8 \mathrm{GHz}$ 


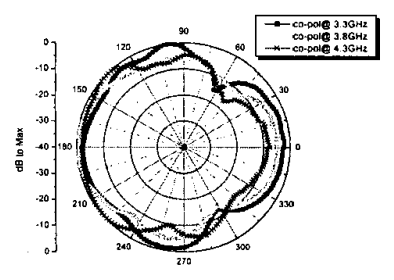

Fig.4. $H$-plane (xz plane) patterns at $3.3,3.8$ and $4.3 \mathrm{GHz}$

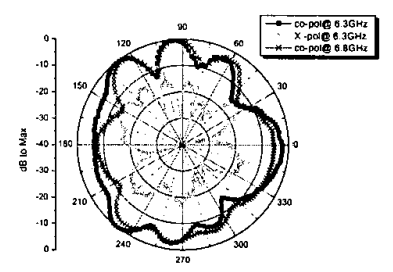

Fig.6. $H$-plane (xz plane) patterns at 6.3 and $6.8 \mathrm{GHz}$ and the crosspolarization at $6.3 \mathrm{GHz}$

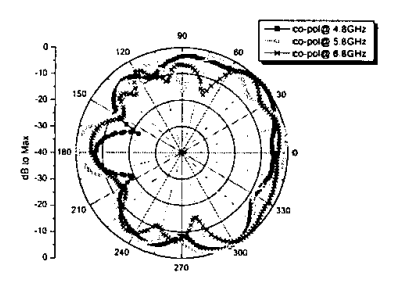

Fig.8. E-plane (xy plane) patterns at $4.8,5.8$ and $6.8 \mathrm{GHz}$

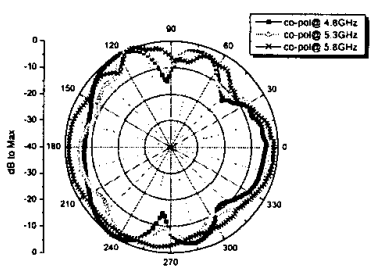

Fig.5. $H$-plane (xz plane) patterns at $4.8,5.3$ and $5.8 \mathrm{GHz}$

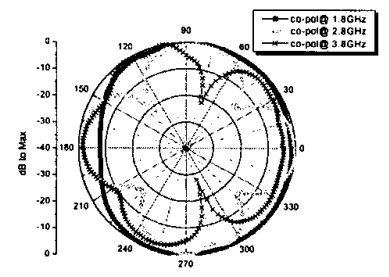

Fig.7. E-plane (xy plane) patterns at $1.8,2.8$ and $3.8 \mathrm{GHz}$

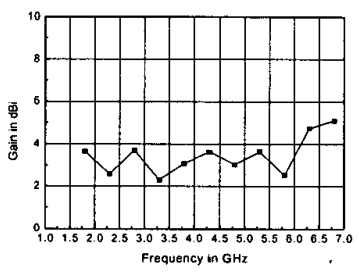

Fig.9. Measured antenna gain versus frequencies 